\title{
No silêncio da clausura: videntes de aparições marianas no Brasil (1928-1937)
}

\author{
In the silence of the enclosure: seers of Marian \\ apparitions in Brazil (1928-1937) \\ El silencio del claustro: videntes de las \\ apariciones marianas en Brasil (1928-1937)
}

MAgno Francisco de Jesus SANTOS iDa

\section{Resumo}

Este trabalho tem como escopo as memórias de duas religiosas que testemunharam visões marianas no Brasil ao longo da primeira metade do século XX. Em 1929 a irmã Amália de Jesus Flagelado (1901-1977), integrante da Congregação das Missionárias de Jesus Crucificado, teria iniciado suas visões de Jesus Manietado e Nossa Senhora das Lágrimas na cidade de Campinas, estado de São Paulo. Essa experiência religiosa foi amplamente divulgada na imprensa e em apenas cinco anos o bispo diocesano, Dom Francisco Campos Barreto, reconheceu as visões e autorizou o terço das Lágrimas. Por outro lado, nos idos de 1936, na vila de Cimbres, estado de Pernambuco, a jovem Maria da Luz Teixeira Carvalho, que passaria a ter o nome religioso de Irmã Adélia (1922-2013), teve a visão de Nossa Senhora das Graças, anunciando os perigos da propagação do comunismo no país. Após as aparições a jovem passou a integrar a Congregação das Damas Cristãs em Recife sob voto de silêncio sobre a questão. Com isso, tenho como problema de investigação a construção da memória sobre as duas visões e as ações de silenciamento e reclusão das videntes no âmbito das clausuras e dos espaços de experiência religiosa visionária. A pesquisa tem como fontes centrais os registros produzidos ao longo da década de 30 do século XX, momento de maior evidência pública das visões, com os questionários realizados por religiosos às videntes no

\footnotetext{
a Universidade Federal do Rio Grande do Norte (UFRN), Natal, RN, Brasil. Doutor em História pela Universidade Federal Fluminense, e-mail: magnohistoria@gmail.com
} 
processo de averiguação diocesana das visões e notícias publicadas na imprensa. Essa documentação foi analisada no sentido de buscar compreender a construção das memórias e dos silenciamentos (POLLAK, 1989), dos usos dos lugares de memórias (NORA, 1993) e das experiências (THOMPSON, 2007) das religiosas no âmbito inicial de constituição de uma cultura política católica anticomunista. Neste caso, a proposta dialoga com a nova história política, no âmbito do conceito de cultura política (RÉMOND, 2003). Nesse sentido, tornou-se possível entender as fissuras e polissemias discursivas no processo de afirmação e esquecimento das visões marianas no Brasil da década de 30.

Palavras-chave: Aparições marianas. Irmã Amália de Jesus Flagelado. Irmã Adélia. Cultura visionária. Brasil.

\section{Abstract}

This work has as its scope the memories of two nuns who witnessed Marian visions in Brazil during the first half of the twentieth century. In 1929, Sister Amália de Flagella Jesus (19011977), a member of the Congregation of the Missionaries of Jesus Crucified, began her visions of Jesus Manietado and Our Lady of Tears in the city of Campinas, state of Sao Paulo. This religious experience was widely publicized in the press and in just five years the diocesan bishop, Dom Francisco Campos Barreto recognized the visions and authorized the third of the tears. On the other hand, in 1936, in the village of Cimbres, state of Pernambuco, the young Maria da Luz Teixeira Carvalho, who would have the religious name of Sister Adelia (1922-2013), had the vision of Our Lady of Graces, announcing the dangers of the spread of communism in the country. After the apparitions, the girl joined the Congregation of Christian Ladies in Recife, on a vow of silence on the issue. With this, I have as research problem the construction of memory on the two visions and the actions of silence and seclusion of the seers within the enclosures and spaces of visionary religious experience. The research has as its central sources the records produced during the thirties of the twentieth century, the moment of greatest public evidence of visions, with questionnaires made by religious to the visionaries in the process of diocesan verification of visions, news published in the press. This documentation was analyzed in order to understand the construction of memories and silences (POLLAK, 1989), the uses of memory places (NORA, 1993) and the experiences (THOMPSON, 2007) of the religious in the initial scope of constitution of a society. anti-communist Catholic political culture. In this case, the proposal dialogues with the new political history, within the concept of political culture (RÉMOND, 2003). In this sense, it became possible to understand the discursive fissures and polysemias in the process of affirmation and forgetting of Marian visions in Brazil of the 1930s.

Keywords: Marian apparitions. Sister Amália of Jesus Flagellated. Sister Adelia. visionary culture. Brazil. 


\section{Resumen}

Este trabajo tiene como alcance las memorias de dos mujeres que presenciaron visiones marianas en Brasil durante la primera mitad del siglo XX. En 1929, la Hermana Amália de Jesús Flagellado (1901-1977), miembro de la Congregación de las Misioneras de Jesús Crucificado, comenzó sus visiones de Jesús Manietado y Nuestra Señora de las Lágrimas, en la ciudad de Campinas, estado de Sao Paulo. Esta experiencia religiosa fue ampliamente informada en la prensa y en solo cinco años el obispo diocesano, Francisco Campos Barreto, reconoció las visiones y autorizó el rosario de las lágrimas. Por otro lado, en 1936, en el pueblo de Cimbres, estado de Pernambuco, la joven María da Luz Teixeira Carvalho, que tendría el nombre religioso de Hermana Adelia (1922-2013), tuvo la visión de Nuestra Señora de las Gracias, anunciando los peligros de la propagación del comunismo en el país. Después de las apariciones, la niña se unió a la Congregación de Damas Cristianas en Recife, en un voto de silencio sobre el tema. Con esto, tengo como problema de investigación la construcción de la memoria en las dos visiones y las acciones de silencio y reclusión de los videntes dentro de los recintos y espacios de la experiencia religiosa visionaria. La investigación tiene como fuentes centrales los registros producidos durante los años treinta del siglo XX, el momento de mayor evidencia pública de visiones, con cuestionarios hechos por religiosos a los visionarios en el proceso de verificación diocesana de visiones, noticias publicadas en la prensa. Esta documentación fue analizada para comprender la construcción de memorias y silencios (POLLAK, 1989), los usos de los lugares de memoria (NORA, 1993) y las experiencias (THOMPSON, 2007) de los religiosos en el ámbito inicial de la constitución de una cultura política católica anticomunista. En este caso, la propuesta dialoga con la nueva historia política, dentro del concepto de cultura política (RÉMOND, 2003). En este sentido, se hizo posible comprender las fisuras discursivas y las polisemias en el proceso de afirmación y olvido de las visiones marianas en Brasil de la década de 1930.

Palabras clave: Apariciones marianas. Amália de Jesús Flagelado. Sor Adelia. Cultura visionaria. Brasil.

\section{Introdução}

Em um contexto totalmente adverso, em tempos sombrios e no espaço da prisão, o historiador Marc Bloch (2001) conclamou os investigadores das coisas passadas a mudarem sua postura diante das fontes. Em suas palavras, "o bom historiador se parece com o ogro da lenda. Onde fareja carne humana, sabe que ali está a sua caça" (BLOCH, 2001, p. 54). O ofício do historiador pautado na postura de um ogro revela inclinações ambivalentes, percursos metodológicos distintos, inquietações historiográficas consideravelmente díspares. 
Nesse caso, retomo as digressões do velho mestre da apologia aos estudos históricos no intuito de repensar o meu caminhar como historiador, que palmilhou os caminhos de Clio entre as experiências educacionais e as práticas religiosas. Afinal, até que ponto os pressupostos de racionalidade metodológica da investigação histórica, gestada Europa Ocidental, permitem a compreensão de uma sociedade complexa como a nossa, na qual a realidade é traçada pelo místico, a vida entrecortada pelo imaginário, a razão salpicada pelo mágico?

O próprio Bloch (1999) aponta um caminho possível. No seminal livro Os reis taumaturgos, revela uma possibilidade de o historiador buscar vencer as barreiras da racionalidade no processo de apreensão do mágico, do fabuloso, da realidade mística que atravessa a vida de numerosos grupos humanos. O intangível pode ser alvo da atenção do historiador que busca não somente a história do milagre, mas, principalmente, a história da crença no milagre. Como um espelho a crença revela os sujeitos de outrora. Ao clamar para o sobrenatural, o íntimo do humano institui uma visibilidade. O humano mágico, sonhador, perscrutador das coisas imaginárias também pode ser alvo da inteligibilidade histórica.

Esse é o desafio que venho enfrentando ao estudar a trajetória de duas mulheres que, assim como as protagonistas de Nas margens, de Natalie Zemon Davis, não chegaram a se conhecer. Duas mulheres que passaram a juventude em espaços distantes, envoltas em realidades opostas. Uma no sertão pernambucano, em terras cercadas por indígenas, em fazendas circundadas por montanhas que eram consideradas a materialidade da Grande Mãe ${ }^{1}$. A outra cresceu na margem oposta do Atlântico, no norte da Espanha, na pequena cidade Riós ${ }^{2}$, entre a mágica cidade de Santiago de Compostela e o majestoso santuário de Bom Jesus de Braga.

\footnotetext{
${ }^{1}$ O Santuário de Nossa Senhora das Graças de Cimbres localiza-se em uma montanha no território indígena do povo Xucuru. Para o povo Xucuru a montanha é a Grande Mãe Terra e o espaço era cultuado antes da aparição. Sobre a relação entre o santuário e as tensões com o povo xucuru existe uma vasta bibliografia com destaque para as pesquisas de Aguiar Neto (2016), Coelho (2017), Neves (1999, 2005), Quérrete (2006), Silva (2016) e Silva (2003).

${ }^{2}$ Riós é um município da província de Orense, na região da Galícia. De acordo com os dados do Instituto Nacional de Estadística (INE) da Espanha, em 1930 a população do município estava em torno de 4.666 habitantes.
} 
Essas mulheres, no ápice da juventude, vivenciaram experiências com o sagrado. Na apoteose dos sentidos, essas mulheres viram, sentiram, ouviram e conversaram com o sagrado, em episódios que podem ser interpretados como aparições marianas no Brasil ${ }^{3}$. Ainda sob o impacto dos milagres de Fátima ${ }^{4}$, as jovens teriam se tornado testemunhas das mensagens marianas que traçavam uma leitura sobre o cenário político do Brasil no entre guerras, tecia uma leitura comum de passado, projetava um projeto comum de futuro. Foram episódios complexos, com recepções ambivalentes, instáveis, tracejada entre a edificação de uma visibilidade e a elucidação de um silenciamento com a imersão do tempo lento da clausura. Sim, na experiência das videntes, o tempo se faz espaço. O espaço se faz tempo. A presença do sagrado propicia o retorno ao tempo mítico, assim como o espaço sagrado da aparição perpetua a experiência temporal.

Uma realidade complexa e marcada por diferentes estratégias de recepção torna a experiência das videntes ambígua, escorregadia. Trata-se de um terreno pantanoso, no qual arrisco os primeiros passos, preocupado, de antemão, com as narrativas tecidas acerca das visões. Mais do que uma pesquisa inicial, apresento as primeiras impressões sobre os episódios vivenciados entre 1929 e 1937.

Ao longo dos anos 30, no Brasil, jovens teriam testemunhado aparições miraculosas da Virgem, portadora de mensagens que denunciavam os perigos do comunismo que poderiam afetar o Brasil e "promover o derramamento de sangue".

\footnotetext{
${ }^{3}$ As aparições marianas constituem um traço importante do catolicismo desde os primeiros momentos. Contudo, a partir do século XIX ocorreram mudanças significativas no perfil das aparições, com a inserção do protagonismo feminino como vidente (anteriormente esse protagonismo era clerical e masculino), a instituição de novos espaços devocionais e as mensagens com um teor de crítica aos elementos tidos como modernos (ciência, racionalidade, secularização, guerras, maçonaria, protestantismo, comunismo e laicização). São casos elucidativos deste novo modelo as aparições de Nossa Senhora das Graças (a Catarina Labouré em Paris, 1830); Nossa Senhora de La Salette (aos pastores Melanie Calvat e Maximin Giraud em La Salette, 1846); Nossa Senhora de Lourdes (a Bernadette Soubirous em Lourdes, 1858); Nossa Senhora de Fátima (aos pastorinhos Lúcia dos Santos, Jacinta Marto e Francisco Marto em Fátima, 1917). As aparições das Graças e de Fátima foram as que tiveram maior difusão nas comunidades católicas brasileiras na primeira metade do século XX. Sobre essa questão confira o artigo de Santos (2017).

${ }^{4}$ Ao longo dos últimos anos da década de 20 do século XX ocorreram as ações de reconhecimento eclesiástico das aparições de Fátima. No dia 3 de maio de 1922 o bispo de Leiria instaurou o processo canônico. No dia 13 de outubro de 1930 o bispo José Alves Correia da Silva torna público que as aparições de Fátima são dignas da fé católica, assim permitindo o culto.
} 
Com isso, em Campinas, no interior paulista, a Virgem teria aparecido para uma religiosa e se intitulado de Nossa Senhora das Lágrimas de Sangue. Poucos anos depois, em Cimbres, Pernambuco, duas jovens camponesas teriam testemunhado a aparição de Nossa Senhora das Graças com as mãos ensanguentadas. Em ambos os casos as mensagens foram apresentadas como o anúncio da tentativa de implantação do novo regime no Brasil. Nas duas situações emergiam devoções atreladas ao sangue que seria derramado pelo povo brasileiro a partir da ameaça comunista.

Diante disso, emerge a necessidade de promover a análise acerca de tais mensagens presentes nos discursos construídos ao longo da década de 30 do século $\mathrm{XX}$, no intuito de encontrar as proximidades e os distanciamentos nos relatos sobre as contemporâneas aparições marianas. Nesse sentido, torna-se salutar, a partir de uma perspectiva comparativa, compreender as trajetórias das videntes, com ênfase para elementos como classe social, família, idade, vinculação com congregações católicas e receptividade das narrativas pelas autoridades eclesiásticas. Tais elementos auxiliam para elucidar a constituição de um perfil acerca de videntes de aparições marianas ao longo do século XX.

O texto tem como fonte privilegiada, na medida do possível, as vozes das videntes. Em decorrência das duas personagens apresentarem trajetórias vinculadas a congregações católicas, a maior parte dos testemunhos encontra-se articulado no processo de construção da memória oficial acerca das visões miraculosas. Nesse sentido, as falas das videntes partem de um lugar social definido e comum da própria instituição. Além disso, nos dois casos, os principais registros foram produzidos no processo de averiguação das visões, em forma de depoimentos prestados a autoridades religiosas, masculinas, como bispos ou padres designados por elas. $\mathrm{O}$ discurso produzido pelas videntes apresenta-se a partir da mediação de sujeitos envoltos na hierarquia católica.

O primeiro caso teve como palco uma nova congregação feminina, o Instituto das Irmãs Missionárias de Jesus Crucificado. Tratava-se de uma congregação criada no dia 3 de maio de 1928, dia da Exaltação da Santa Cruz. A congregação teve como origem a partir de uma associação religiosa, liderada pela devota da Sagrada Paixão de Cristo, Maria Villac. Foi o bispo da Diocese de Campinas, Dom Francisco de Campos Barreto, que convidou Maria Villac para transformar a associação em uma 
congregação religiosa. Portanto a congregação na qual ocorreu a aparição tinha como fundador o bispo diocesano.

A vidente das aparições marianas foi a irmã Amália Aguirre. Ela nasceu no dia 22 de julho de 1901, em Riós na Espanha, filha de Andres e Emerita Aguirre. Após o final da Primeira Guerra Mundial, em 1919, juntamente aos seus seus pais veio ao Brasil. Oriunda de família religiosa, ela integrou-se ao grupo liderado por Maria Villac e, em 1928, deu início a sua vida religiosa na Casa-Mãe de Campinas, onde o Bispo Dom Francisco de Campos Barreto havia criado a nova congregação. A Irmã Amália Aguirre integrava o grupo das primeiras religiosas que recebeu o hábito de noviciado no dia 11 de maio de 1928. Descrita nos documentos como uma mulher de aparência frágil e com parcos conhecimentos teológicos, ela se tornaria o centro das atenções da congregação nos seus primeiros anos.

Figura 1 - Irmã Amália Aguirre em 1928, Campinas

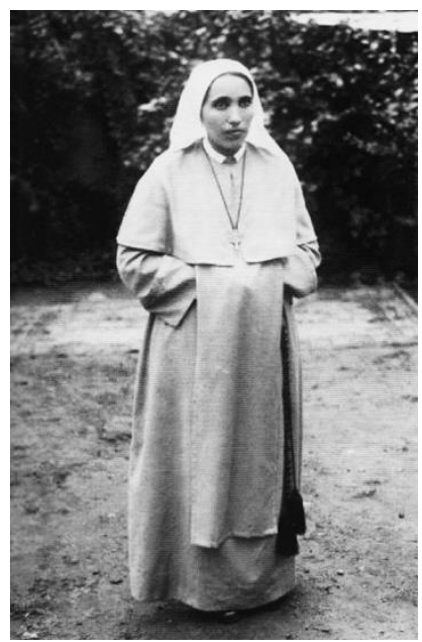

Fonte: Missionários das Lágrimas de Maria.

As visões sagradas da Irmã Amália Aguirre tiveram início em 1929. Primeiramente teria ocorrido a aparição de Jesus Manietado, uma devoção diretamente associada à nova congregação. A parti desse momento a irmã teria iniciado as suas visões de Jesus Cristo e de Nossa Senhora. Nos idos de 1931 a religiosa professou os votos perpétuos e adotou o nome religioso de irmã Amália de Jesus Flagelado. Em 1953, transferiu-se para Taubaté, onde fundou uma nova casa. No dia 18 de abril de 1977 faleceu em Taubaté com fama de santa. 
O fenômeno das aparições de Campinas teve como vidente apenas a Irmã Amália de Jesus Flagelado. Ela torou-se a única testemunha das mensagens deixadas por Cristo e por Nossa Senhora. Contudo, a experiência da religiosa foi amplamente divulgada na imprensa e testemunhado por religiosos da alta cúpula eclesiástica, jornalistas e médicos. Dessa experiência visionária, emergiu uma nova devoção mariana em terras brasileiras: Nossa Senhora das Lágrimas de Sangue.

No dia 8 de março de 1930, na capela do Instituto das Irmãs Missionárias de Jesus Crucificado, a Irmã Amália de Jesus Flagelado testemunhou a aparição de Maria, autoproclamando-se Nossa Senhora das Lágrimas. Nessa aparição a visão expressou os seus pedidos e pediu a difusão de novos objetos e práticas devocionais, como a Medalha das Lágrimas e o Terço das Lágrimas de Sangue. Além disso, na aparição, a Virgem repetiu o pedido que vigorou em outros fenômenos similares ocorridos em outras partes do mundo anteriormente, com os votos por oração, sacrifício e penitência. Esse seria o caminho para salvar o Brasil de uma investida comunista e das ameaças do inferno. O Brasil adentrava no cenário internacional das aparições e da ameaça comunista ${ }^{5}$.

As visões em Campinas explicitam alguns elementos peculiares, se compararmos com experiências visionárias do mundo contemporâneo. Uma questão relevante foi a da visibilidade do fenômeno no âmbito da imprensa. Com isso, desde as primeiras manifestações, a imprensa tornou-se presente com a descrição dos episódios e a sugestão de se tratar de "circunstâncias sobrenaturais" (CORREIO POPULAR, 1929, p. 1). No dia 14 de novembro de 1929 foi publicada uma matéria com a apresentação dos principais episódios que tinham ocorrido em Campinas.

\begin{abstract}
Uma religiosa, de nacionalidade hespanhola, que adoptou o nome de Amália de Jesus Flagelado, vem soffrendo diariamente em horas diversas, todos os symptomas de uma estygmatização, cahindo após e, profundo extase durante o qual fala com Jesus Christo e prega a mais linda doutrina catholica, expendendo conhecimentos muito superiores aos
\end{abstract}

\footnotetext{
${ }^{5}$ Ressalta-se que essa não foi a primeira experiência visionária no país, nem tampouco, o registro inaugural de contato de um religioso com a dimensão sagrada. No país ainda se falava do impacto do chamado "Milagre do Juazeiro", centrada na figura da beata Maria de Araújo, que no dia primeiro de março de 1889 protagonizou o Milagre da Hóstia na comunhão com o Padre Cícero. Esse milagre originou a primeira grande romaria do Juazeiro em devoção ao Santíssimo Sangue de Jesus. Sobre essa questão pode ser consultado os textos de Nobre $(2010 ; 2014)$ e Teixeira (2015).
} 
seus próprios que são "rudimentares". Hontem, a santa religiosa, como já está sendo chamada nesta cidade, teve uma crise mais forte (CORREIO POPULAR, 1929, p. 1).

A aparição e o fenomeno dos estigmas tornram-se alvo da imprensa com a realização de matérias jornalísticas. O texto publicado no jornal Correio Popular expressa o episódio como isento de questionamento. Pelo contrário, os episódios atinentes à visão da Irmã Amália eram descritos como dignos da fé, sinais tangíveis das virtudes da religiosa e dos prodígios da nova congregação. Desse modo, tanto os jornalistas quanto as autoridades religiosas da Diocese enfatizavam o caráter sagrado das manifestações, circunscritas pela expressão de conhecimentos da doutrina cristã, aparentemente inacessíveis para uma religiosa de conhecimentos "rudimentares". O periódico campineiro expressou:

\footnotetext{
Manifestações Místicas de uma religiosa do "Instituto Missionário de Jesus Crucificado" - Em seus Extases, Estigmatizada, Sóror Amélia de Jesus Flagelado prega a mais linda doutrina Católica, revelando conhecimentos superiores aos seus próprios, que são rudimentares. - O Sr. D. Francisco Barreto, bispo diocesano, concede uma entrevista a um jornalista sobre o interessante caso. - A curiosidade popular em torno do fato sobrenatural. — Notas diversas (CORREIO POPULAR, 1929, p. 1).
}

O milagre era descrito com detalhes. O sinal apresentado como prova inconteste da manifestação sagrada eram os estigmas. O corpo da religiosa tornavase sinal tangível do poder miraculoso, as feridas na carne expressavam $O$ compartilhamento das dores da Paixão. Nesse caso, os estigmas expressavam mais do que sinais no corpo. Eram fissuras no tempo, que levavam a Irmã Amália para o tempo mítico da Paixão de Cristo. Pelos estigmas a irmã compartilhava a experiência da Paixão em um deslocamento no tempo e no corpo.

No caso de Campinas, as aparições poderiam ser expressas em duas oportunidades: em 1929 com a manifestação do próprio Cristo, da qual emergiria a devoção a Jesus Manietado (amarrado), e em 1930 com a visão de Nossa Senhora das Lágrimas. Na aparição do dia 8 de abril de 1930 Nossa Senhora teria pedido para que fossem produzidas as medalhas devocionais. Confira a Figura 2. 
Figura 2 - Medalhas de Jesus Manietado e Nossa Senhora das Lágrimas

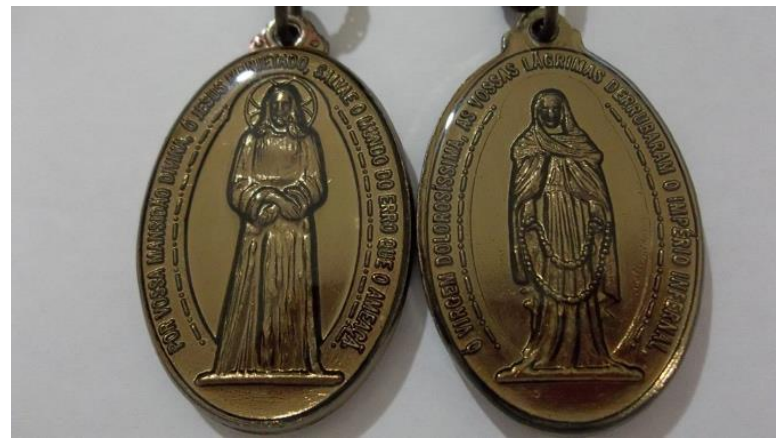

Fonte: Missionários das Lágrimas de Maria.

A visão da Virgem em Campinas é o elemento central da experiência miraculosa. Um indício disso é a pouca atenção atribuída à visão de Jesus Manietado nos idos de 1928. Neste ano, a Irmã Amália de Jesus Flagelado teria testemunhado uma visão de Cristo. Essa descrição de uma manifestação anterior, como preparação das visões subsequentes, assemelha-se ao fenômeno de Fátima, na qual as memórias das Irmã Lúcia elucidam que ao longo de 1916 os três pastorinhos teriam visto o "Anjo de Portugal" (SANTOS, 2017). Nos dois casos, tanto as visões do anjo como a de Jesus Manietado teriam sido um prenúncio das visões marianas que ocorreriam no ano seguinte, ou seja, a visão mariana emerge como a centraldiade dos fenômenos.

No texto publicado no Correio Popular, marcado por inúmeros comentários, explicações teológicas e doutrinárias do bispo diocesano Dom Francisco Barreto, a trajetória da Irmã Amália de Jesus Flagelado é apresentada com um viés hagiográfico. Os traços da vida da religiosa são apresentados em âmbito comparativo, em uma estratégia que atrela a vida de Irmã Amália à trajetória de santos reconhecidos pela Igreja Católica. A experiência foi apresentada como algo inexplicável, fora do âmbito da ciência, ou seja, como um sinal divino entre os homens.

Campinas, 13 - Há dias que vêm correndo pela cidade a Notícia de que, no "Instituto Missionário Jesus Crucificado", situado a Rua Dr. Quirino 77, estabelecimento religioso fundado pelo D. Francisco de Campos Barreto, bispo diocesano, um facto inédito, que escapa do poder da ciência médica. Ali se vem passando por circunstâncias sobrenaturais, está preocupando os espíritos mais fortes, tecendo uma lenda de Santidade em torno de uma Irmã de caridade daquele acolhimento (CORREIO POPULAR, 1929, p. 1).

Nesse caso, as visões, as mensagens e os estigmas da religiosa do Instituto Missionário Jesus Crucificado seriam uma reafirmação dos mistérios devocionais 
difundidos em outras plagas e, possivelmente, o agraciamento divino da nova congregação criada em Campinas pelo Bispo Dom Francisco de Campos Barreto e pela Madre Maria Villac, no dia 3 de maio de 1928, dia da Invenção da Santa Cruz. O jornal apresentou a seguinte narrativa:

No dia 17 de agosto manifestou-se o primeiro estygma, semelhante ao de São Francisco de Assis e o de Gemma Galgani, na Itália, abrindo-Ihe feridas gottejantes em ambas as mãos, tanto no dorso, quanto na palma, nos pontos exactos em que as de Jesus foram varadas pelos pregos na cruz [...]. as manifestações de estymatizada se revelam em soro Amalia quase diariamente, sendo a mais suppliciante a da que relembra a coroa de espinhos que flagellou Nosso Senhor. Nesses momentos, da testa muito clara da religiosa aprofundam-se golpes produzidos por espinhos e o sangue jorra abundante. Seu martyrio é inenerrável. Em uma dessas occasiões, foi chamado o dr. Falcão de Miranda, o qual, em attestado, que se acha em poder de d. Barreto, declaro não se tratar de um caso de clínica. Pela primeira vez, hontem, das 7 horas e meia as 10 e meia da manhã, a piedosa irmã soffreu toda a tortura da grande paixão de Jesus, sendo este facto presenciado por s. exc. O sr. Bispo, de todas as irmãs do Instituto e diversas pessoas. Durante essas manifestações Amália de Jesus Flagellado permaneceu num estado que não se pode definir de cataleptico, pois não está nem dormindo, nem sonhando, nem acordada. Não dorme porque responde a todas as perguntas, não sonha porque fala com precisão, não está acordada porque não sente dores physicas, como picadas de alfinetes, fricções, etc. Taes foram as palavras de Dom Francisco de Campos Barreto, que as disse - frisou bem a s. ex. - com as devidas reservas, pois o facto continua a merecer accurado estudo e será a Santa Sé que definirá, esclarecendo-o devidamente (CORREIO POPULAR, 1929, p. 1).

Um elemento incomum nas aparições de Campinas é a tutela do bispo diocesano, que desde o primeiro momento demonstrou apoio e reconhecimento sobre a causa. Prova disso é a autorização imediata do Terço das Lágrimas e da Medalha das Lágrimas para serem disseminados em âmbito diocesano por meio do Imprimitur assinado em 8 de março de $1932 .{ }^{6}$ Em 1934 ele prefaciou o primeiro livro que discutiu as visões da Irmã Amália de Jesus Flagelado acerca de Cristo Manietado e de Nossa Senhora das Lágrimas, intitulado Glórias e poder de Nossa Senhora das

\footnotetext{
${ }^{6}$ A devoção não ficou circunscrita ao âmbito diocesano de Campinas. Ressaltam-se outras aprovações eclesiásticas em diferentes países: Imprimatur do Bispo Francisco de Campos Barreto, Diocese de Campinas, São Paulo (Brasil), 8 de março de 1932. Imprimatur do Bispo Michael James Gallagher, Diocese de Detroit, Michigan (Estados Unidos), 22 de março de 1935. Imprimatur do Arcebispo John Robert Roach, Arquidiocese de Saint Paul em Minneapolis, (Estados Unidos). Nihil obstat no 924/1935, de Ansgarus Borsiczky, Censor Diocesano em Sopron (Hungria), no dia 25 de maio de 1935. Imprimatur do Bispo Stephanus Breyer, Diocese de Győr (Hungria), no dia 13 de julho de 1935. Imprimatur do Vigário Geral Ferdinand Buchwieser, Arquidiocese de Munique e Frisinga (Alemanha), no dia 22 de março de 1935.
} 
Lágrimas. Tratava-se de uma obra que apresentava as aparições como um fenômeno miraculoso, explicado como uma graça divina. Contudo, apesar do apoio instituído pelo bispo, as mensagens da aparição e a devoção a Nossa Senhora das Lágrimas tornaram-se pouco representativas e ainda não foram aprovadas pela Santa Sé. Apesar de ter ocorrido uma difusão diocesana no primeiro momento, nos anos subsequentes houve um silêncio acerca dos episódios de Campinas, possivelmente, em decorrência da morte do principal entusiasta das visões, Dom Francisco de Campos Barreto, nos idos de 1941.

A segunda aparição ocorreu no Nordeste brasileiro, na vila de Cimbres, município de Pesqueira, em Pernambuco. Esse episódio teve como videntes duas jovens camponesas que saíram pelo matagal no intuito de colher mamonas. ${ }^{7}$ Eram Maria da Luz Teixeira e Maria da Conceição. As jovens ouviram um grande estrondo e viram "um raio de fogo cortar o céu. Ao se aproximar de um rochedo, as duas meninas teriam visto Nossa Senhora, apresentando-se como Virgem das Graças e que se encontrava com as mãos ensanguentadas" (SANTOS, 2017). De acordo com a narrativa do Padre Kehrle (1941, p. 3):

Foi no ano de 1936, dia 6 de agosto, que Arthur Teixeira mandou que sua filha Maria da Luz, junto com Maria da Conceição fossem ao sítio colher as sementes de Mamona. Obedientes, seguiram as duas, conversando sobre o tempo passado de perseguição e perigo. Em dado momento, Maria da Luz perguntou a sua companheira: "o que você faria se agora mesmo chegasse aqui Lampião?" Imediatamente esta respondeu: Nossa Senhora haveria de dar-nos um jeito para este malvado não nos ofender". E, olhando em direção à Serra, ficou por um tempo surpreendido. Parecia ver no alto da Serra uma imagem em forma de mulher com uma criança que lhe fazia sinais com a mão. Apontando para a Serra, disse bem alto: "Olha lá uma imagem!" Maria da Luz olhou na direção apontada e também viu a imagem. "Uma mulher bonita, com um menino nos braços"

O registro do Padre José Kehrle (1941), um dos religiosos responsáveis pela averiguação das aparições, elucida a experiência visionária das duas jovens em articulação com contexto marcado pela violência de grupos de jagunços. O medo do deslocamento é o enredo que demarca a saída das jovens. Contudo a visualização da imagem de Nossa Senhora não é descrita como uma visão de temor. Pelo contrário, aparece como um alívio, uma resposta sagrada pelos pedidos de proteção.

\footnotetext{
${ }^{7}$ Ricinus comunis. 
O sangue nas mãos da Virgem foi associado à ameaça da expansão do comunismo no Brasil, pois "o sangue que seria derramado no país com a chegada do comunismo" (KEHRLE, 1941, p. 35). Sobre a trajetória de Maria da Conceição quase nada há divulgado. Sabe-se apenas que era de origem humilde e que foi criada pela família de Maria da Luz. De acordo com Ana Lígia Lira (2014, p. 156), ela nasceu em 1920 e faleceu em 1999.

Trata-se de uma trajetória que se aproxima ao de outra mulher brasileira que teve uma experiência religiosa alguns decênios antes. Maria da Conceição apresentava condições sociais similares ao da beata Maria de Araújo, a beata do Milagre da Hóstia no Juazeiro do final do século XIX. Assim como a beata Araújo, Maria da Conceição foi silenciada, impossibilitada de ingressar em uma congregação religiosa e viveu em situação de pobreza com votos de castidade. Trata-se de uma mulher que foi marginalizada, permanecendo fora do âmbito institucional.

Já em relação à trajetória de Maria da Luz existe uma documentação mais consistente, pois ela ingressou em uma congregação católica. Ela entrou na Congregação das Damas em Recife e permaneceu na capital pernambucana até o falecimento em 2013. Uma questão que destoa em relação ao caso anterior é a ausência de uma comissão para o estudo das aparições. Como elucida Dom Rafael Maria Francisco da Silva, "todo o interesse no suposto Santuário se manteve pelas “construções" rentáveis, mas nunca se ouviu falar de uma Comissão Teológica para estudar a veracidade das aparições" (SILVA, 2016, p. 47). A devoção oriunda das visões perpassa por outras inquietações, como o conflito acerca das terras da localidade onde teria ocorrido a aparição, envolvendo os índios Xucuru.

Outro elemento relevante no caso da aparição de Cimbres é a data. O episódio inaugural teria ocorrido no dia 6 de agosto, dia da Festa Litúrgica da Transfiguração de Jesus. O primeiro dia foi marcado por duas aparições: a primeira, pela manhã, foi testemunhada pelas duas meninas, que estavam sozinhas e apenas contemplaram a imagem, sem diálogo. Pela tarde, o pai de Maria da Luz acompanhou as duas meninas para a Serra do Ororubá para ver o que tinha ocorrido. No mesmo local as duas meninas mostravam com entusiasmo a imagem, mas Arthur nada via. Foi nessa ocasião que ocorreu o primeiro diálogo com a mensagem mariana: 
Quem é você? Perguntou Maria da Luz, e a imagem respondeu: "Eu sou a Graça".

Que quer a Senhora aqui? Perguntou Maria da Luz novamente.

Respondeu a aparição: "vim para avisar que hão-de vir três castigos mandados por Deus".

E com pouco continuou: "Digam ao povo que reze e faça penitência" (SILVA, 2016, p. 68).

A primeira mensagem mariana em terras pernambucanas é marcada pela ameaça de castigo divino, um sinal da insatisfação com o destino político do país. $\mathrm{O}$ Brasil foi apontado como um espaço ameaçado. O caminho da salvação perpassa pela busca de orações e de penitencias. Era necessário purgar pelos erros cometidos. Mas quais erros? Quais eram os motivos dos castigos?

Essas informações não apareceram nas primeiras mensagens. Até mesmo no inquérito realizado no local das aparições, com a presença das duas videntes acompanhadas pelo padre Manoel Marques e Frei Estévão Roetgger, no dia 10 de setembro de 1936, os dados aparecem imprecisos. De acordo com o Padre João Maria Lombaerde (1939, p. 37), o inquérito apresentou o seguinte diálogo:

Que é necessário fazer para desviar os castigos? - "Penitência e oração".

Qual a invocação desta aparição? - "Das Graças".

Que significa o sangue que corre das vossas mãos?

- "O sangue que inundará o Brasil".

Virá o comunismo a penetrar no Brasil? - "Sim".

Em todo o País? - "Sim".

Também no interior? - "Não".

Os padres e os bispos sofrerão muito? - "Sim".

Será como na Espanha? - "Quase".

Quais as devoções que se devem praticar para afastar esses males? - "Ao coração de Jesus e a mim".

Esta aparição é a repetição de La Salette? - "Sim".

No livro de Lombarde (1939), os elementos anticomunistas aparecem com maior precisão. A aparição da Virgem seria um sinal dos novos tempos que ameaçavam adentrar no país. O comunismo, o sangue derramado, o exemplo da Guerra Civil Espanhola, foram elementos que aproximaram as aparições da cultura política católica dos anos 30, nas quais o anticomunismo se tornava uma questão nodal.

Nesse sentido, as mensagens marianas divulgadas pelas videntes, ressaltam-se um elemento em comum: a preocupação com a expansão do comunismo pelo mundo. O poderio político soviético o longo da década de 30 do século XX é descrito como 
uma ameaça ao mundo católico e somente a junção de reza, penitência e sacrifício poderiam inibir a expansão dessas ideias por novos países, como Portugal (momento no qual a Irmã Lúcia escreve o diário com as primeiras referências às ameaças da Rússia comunista) e Brasil.

Como expressa a medalha devocional de Campinas, a dedicação a Jesus Manietado poderia "salvar o mundo do erro que se acha ameaçado". Isso ocorreu justamente no período no qual Brasil estava vivendo uma importante articulação entre o clero católico e o poder estatal com a difusão de uma cultura política varguista que tentava reinventar a sua identidade nacional, pautada no uso das tradições, no revigoramento do catolicismo e com a ênfase em ruptura política a partir da designação do Estado Novo.

Passado e presente coadunavam na construção de uma cultura política católica anticomunista. As representações da Virgem e do Cristo expressam a dor com as imagens cabisbaixas, de certo modo, constrangidas pelos desvios humanos. O rosário, por sua vez, aparece como o foco de luz que poderia converter o povo e derrubar o “império infernal”. Nas duas iconografias, destacam-se os cenários: a Virgem aparece como se tivesse descido do altar, vestida de roxo, com expressão triste e lacrimosa, para entregar a vidente o seu rosário de lágrimas. Trata-se de uma representação similar ao da Virgem dolorosa. 
Figura 3 - Nossa Senhora das Lágrimas e Jesus Manietado

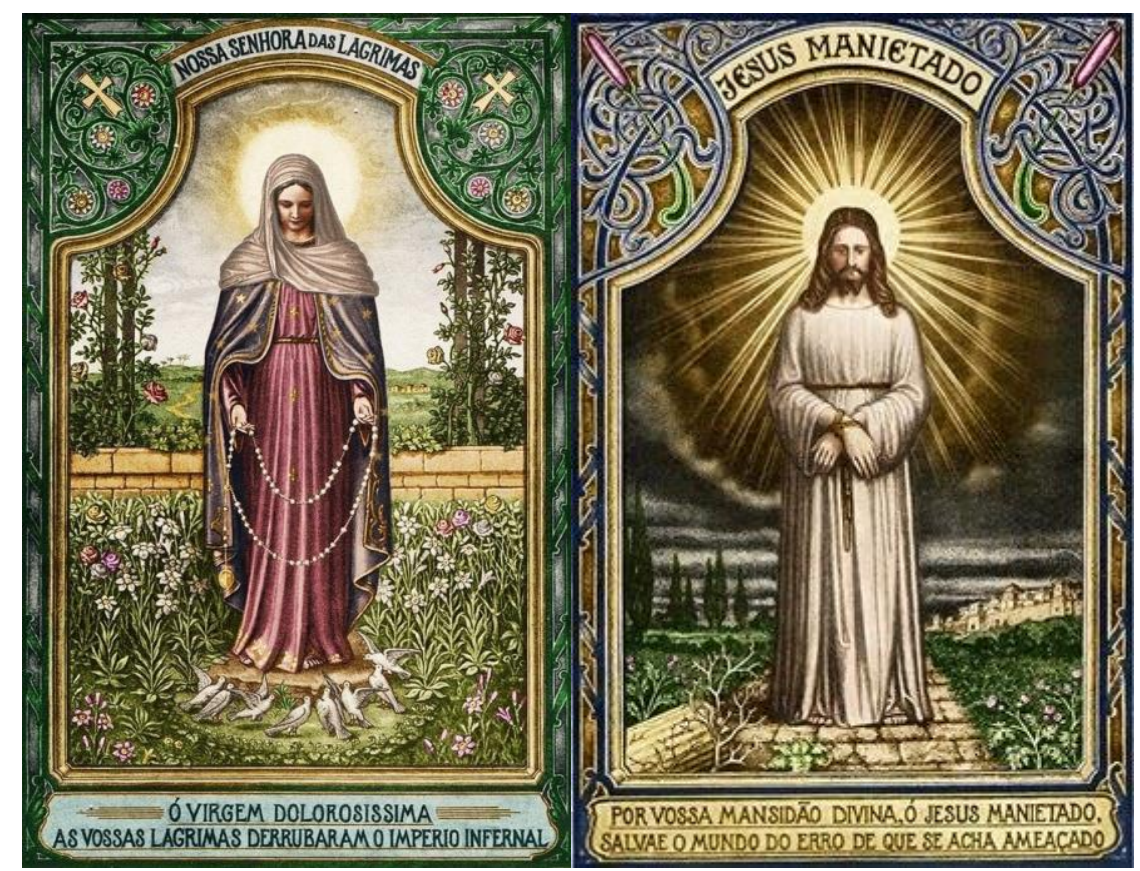

Fonte: Missionários das Lágrimas de Maria.

O Cristo, todavia, aparece em um cenário diferenciado, como se remetesse à antiga Jerusalém. De um lado aparece no horizonte a velha cidade cercada pelas muralhas. Do outro, um jardim. Próximo aos pés do "Manso Cordeiro" aparece o fragmento de uma coluna, como o indício de uma demolição, sinalizando a decadência que ameaça o mundo.

A própria intitulação das duas novas devoções elucida a aproximação entre a tradição católica devocional do país e a emergência de uma cultura visionária moderna. Nossa Senhora das Lágrimas de Sangue remete à Virgem dolorosa, testemunha dos martírios de Cristo. Trata-se de uma devoção recorrente na sociedade brasileira, principalmente, entre os segmentos sociais marginalizados.

O Jesus Manietado, apesar de possuir um título diferenciado das devoções populares, apresentava uma iconografia que dialogava com o repertório devocional das camadas populares por meio da devoção do Bom Jesus. Tratava-se do Cristo amarrado e apresentado ao público, muito similar ao ícone do Ecce Homo, devoção predileta da população do interior paulista em santuários como o de Pirapora do Bom Jesus, Bom Jesus dos Perdões, Bom Jesus do Braz, Bom Jesus de Tremembé e Bom Jesus do Iguape. Além disso, tanto Nossa Senhora das Lágrimas, quanto o Cristo 
Manietado eram devoções associadas diretamente à Congregação das Irmãs de Jesus Crucificado, criado pelo bispo de Campinas e que tinha como expressão central a difusão das práticas penitenciais em torno do calvário.

Ao contrário da aparição de Campinas, que teve como lastro devoções tradicionais do catolicismo das camadas populares no Brasil, centradas nos episódios da Paixão, o fenômeno de Cimbres teve como respaldo o diálogo com as modernas aparições do mundo Europeu, incluindo a repetição da titulação mariana. A mensagem da Virgem reproduzida pela vidente revela a confirmação da reforma devocional católica, empreendida no país desde o final do século XIX, com o reforço a difusão do culto a Nossa Senhora das Graças e do Sagrado Coração de Jesus.

O processo de reconhecimento das autoridades da Igreja Católica acerca das aparições ocorreu em um momento crucial, um ano após a eclosão da chamada Intentona Comunista. O socialismo e a União Soviética não eram tidos como ameaça distante e desconexa em relação à possibilidade de o Brasil ingressar na seara socialista. Pelo contrário, as autoridades elencavam o medo presente nos anseios sociais e na própria impressa do perigo de ocorrer uma revolução no país.

A Igreja católica, por meio de suas narrativas miraculosas, reafirmava esse medo e propagava uma cultura histórica na qual o comunismo era tido como uma das armas mais ferozes. As mensagens marianas preconizam uma ação mediada pelas orações como forma de reparar os danos provocados pela descrença. Como destacou o padre Lombaerde (1940, p. 61), “as advertências de Nossa Senhora eram reiteradas: pedia sempre e insistia que era preciso rezar; senão seu Filho castigaria severamente o Paiz”. Por outro lado, o medo do comunismo já estava proliferado pelo Brasil. Um indício desse medo está presente na Carta Pastoral da Província Eclesiástica da Bahia, publicada em 1931.

Não há dúvida de que o Brasil atravessa hoje a hora talvez mais grave de sua história. E já começam a aparecer sinais inequívocos de que a onda rubra da Rússia soviética caminha a passos agigantados para o Brasil, trazendo-Ihe o cortejo dos horrores sociais que todos hoje conhecemos e que é bom experimentarmos nas lições formidáveis de outros países, para acudir a ruína do nosso (SILVA, 1931, p. 3).

Essa visão do clero difundida em um documento eclesiástico revela como a concepção anticomunista era difundida pelo Brasil dos anos 30 do século XX. 
Certamente tais ideias eram proliferadas nos sertões, por meio das homilias apresentadas pelos párocos em seus púlpitos e deve ter contribuído para constituir uma leitura de mundo na qual a Rússia era representada como uma experiência espacial do inferno terreno, a porta de entrada das ideias perigosas. Nesse sentido, as mensagens marianas difundidas no país por meio das videntes se coadunavam com os interesses da cúpula da Igreja Católica, reafirmando como a corte celestial temia sobre o futuro do Brasil na condição de nação.

Contudo a perspectiva anticomunista não foi exclusiva do governo brasileiro. Entre 1928 e 1937 a Santa Sé publicou seis documentos para discutir a propagação do comunismo em países como Rússia, México e Espanha e reiterar as ações das nações católicas e da imprensa no processo de resistência e combate aos ideais marxistas. O Vaticano alinhou-se às nações do mundo ocidental, com a difusão de cultura política católica anticomunista, ao publicar documentos nos quais denunciavam as mazelas do comunismo.

Em 19 de março de 1937, dia de São José, patrono da família católica, Pio XI (1937) publicou o documento que elucidava uma postura de maior criticidade e combate ao comunismo, no qual elucidava os riscos das pretensões de propagação dos ideais por todo o mundo. Timidamente o documento consagra a população russa à Igreja Católica, tida como a instituição paternal que reconhecia a condição de escravidão e enganação na qual os russos estariam subjugados.

Tanto Campinas quanto Cimbres explicitaram os desvios da humanidade e o caminho da redenção por meio da oração e da penitência. Todavia, apesar de existir um relativo apoio de algumas autoridades religiosas em ambos os casos, as aparições brasileiras dos anos 30 reverberaram apenas no decênio posterior a visão. Com a morte dos seus defensores, os processos foram esquecidos e as devoções paulatinamente silenciadas com o retorno da prudência. Em Campinas, após a morte de Dom Francisco de Campos Barreto, em 1941, a devoção a Nossa Senhora das Lágrimas foi transplantada para os bastidores. A capela onde teria ocorrido a aparição foi fechada para o acesso público, tornando-se acessível apenas para as Irmãs Missionárias de Jesus Crucificado. A imagem devocional da Virgem das Lágrimas, exposta no altar da catedral, foi retirada e levada para a capela conventual. De modo 
similar, o livro Glórias e Poder de Nossa Senhora das Lágrimas desapareceu do acervo das bibliotecas católicas.

No caso de Cimbres a situação foi ainda mais complexa. O padre Kehrle foi afastado da paróquia de Pesqueira e o silêncio sobre as aparições perpassaram as trajetórias da Irmã Adélia e de Maria da Conceição. Com a morte do padre Kehrle, de Frei Estêvão Rottiger e da vidente, a documentação foi fragmentada, dificultando a reabertura do processo. Além disso, a localização do santuário das aparições em terras dos índios Xucurus dificultou o acesso dos devotos, em decorrência dos inúmeros conflitos envolvendo fazendeiros e índios disputando a posse das terras. Contudo, apesar do reconhecimento das especificidades nas duas experiências visionárias, torna-se salutar entender como a tradição católica devocional a Nossa Senhora tornou-se o lastro para a divulgação de diferentes propostas de culturas políticas, respaldadas nos usos do passado e na edificação de um futuro guiado pelas mensagens. A crença nos milagres tornou-se um elemento importante na reconciliação entre a Igreja Católica e o Estado na edificação de um projeto de nação no Brasil.

\section{Referências}

AgUiAR NETO, M. R. B. de. Maria, Mariana na Serra do Ororubá - PE (1936-2016). 2016. Dissertação (Mestrado em Ciências da Religião) - Universidade Católica de Pernambuco, Unicap, Recife, 2016.

BLOCH, M. Apologia da História on o ofício do historiador. Tradução de André Telles. Rio de Janeiro: Zahar, 2001.

BLOCH, M. Os reis taumaturgos: o caráter sobrenatural do poder régio na França e Inglaterra. Tradução de Júlia Mainardi. São Paulo: Companhia das Letras, 1999.

COELHO, H. F. Povo xukuru do Ororubá: conflitos fundiários e nova administração no território indígena em Pesqueira e Poções/PE. 2017. Trabalho de Conclusão de Curso (Bacharelado em Arquitetura) - Faculdade Damas da Instrução Cristã, Recife, 2017.

CORREIO POPULAR. Em Campinas. Correio Popular. 1929, p. 1.

DAVIS, N. Z. Nas Margens: três mulheres do século XVII. São Paulo: Companhia das Letras, 1997.

ELIADE, M. O sagrado e o profano. Tradução de Rogério Fernandes. São Paulo: Martins Fontes, 1992. 
INSTITUTO DAS MISSIONÁRIAS DE JESUS CRUCIFICADO. Haciendo História. Campinas: IMJC, 2010.

GOMES, Â. de C. A cultura histórica do Estado Novo. Projeto História, n. 16, p. 121-141, 1998.

KEHRLE, J. Manuscripto. Recife: [s.n.] 1941.

LIRA, A. L. O Diário do Silêncio. Rio de Janeiro: Nova Terra, 2014.

LOMBAERDE, J. M. de. O Fim do Mundo está próximo! Profecias antigas e recentes. 2. ed. Rio de Janeiro: Boa Imprensa, 1939.

MISSIONÁRIOS das Lágrimas de Maria (MLM). Irmã Amália Aguirre em 1928, Campinas. Missionários das Lágrimas de Maria. Disponível em: <https://missionarios-daslagrimas.webnode.com>. Acesso em: 10 maio 2019.

MISSIONÁRIOS das Lágrimas de Maria (MLM). Medalhas de Jesus Manietado e Nossa Senhora das Lágrimas. Missionários das Lágrimas de Maria. Disponível em: $<$ https://missionarios-das-lagrimas.webnode.com>. Acesso em: 12 set. 2019.

MISSIONÁRIOS das Lágrimas de Maria (MLM). Nossa Senhora das Lágrimas e Jesus Manietado. Missionários das Lágrimas de Maria. Disponível em: <https://missionarios-daslagrimas.webnode.com>. Acesso em: 12 set. 2019.

MOURA, C. A. S. "Não tenhas medo": a formação de uma cultura visionária em Portugal e as suas práticas e representações no Brasil (1917-1940). Topoi, v. 17, n. 33, p. 561-585, 2016.

NEVES, R. de C. M. Dramas e performance: o processo de reelaboração étnica Xukuru nos rituais, festas e conflitos. 2005. Tese (Doutorado em Antropologia) — Universidade Federal de Santa Catarina, Florianópolis, 2005.

NEVES, R. de C. M. Festas e mitos: identidades na Vila de Cimbres-PE. 1999. Dissertação (Mestrado em Antropologia) — Universidade Federal de Pernambuco, Recife, 1999.

NOBRE, E. dos S. O teatro de Deus: a construção do espaço sagrado de Juazeiro do Norte a partir das narrativas femininas (Ceará, 1889-1898). 2010. Dissertação (Mestrado em História) — Universidade Federal do Rio Grande do Norte, Natal, 2010.

NOBRE, E. dos S. Incêndios da Alma: a Beata Maria de Araújo e a experiência mística no Brasil do Oitocentos. 2014. Tese (Doutorado em História) - Universidade Federal do Rio de Janeiro, UFRJ, Rio de Janeiro, 2014.

NORA, P. Entre memória e História: a problemática dos lugares. Revista Projeto História, n. 10, p. 7-28, 1993.

PIO XI. Carta Enciclica Divinis Redemptoris: De Sua Santidade Papa Pio XI Aos Veneráveis Irmãos, Patriarcas, Primazes, Arcebispos, Bispos e Demais Ordinários. Em Paz e Comunhão com a Sé Apostólica sobre o Comunismo Ateu. Vaticano, 1937.

PIO XI. Littera Apostolica B. M. V. Immaculata Sub Titulo “Apparecida” Principalis Patrona Brasiliæ Constituitur (16 de julho de 1930). In: PIO XI. Acta Ap. Sedis, v. 23, 1931. p. 7. 
POLLAK, M. Memória, esquecimento, silêncio. Revista Estudos Históricos, v. 2, n. 3, p. 3-15, 1989.

QUÉRRETE, L. L. Onde o céu se encontra com a terra: um estudo antropológico do Santuário Nossa Senhora da Graça na Aldeia Guarda, em Cimbres (Pesqueira-PE). 2006. Dissertação (Mestrado em Antropologia) — Universidade Federal de Pernambuco, Recife, 2006.

RÉMOND, R. Por uma história política. Trad. Dora Rocha. Rio de Janeiro: FGV, 2003.

SANTOS, M. F. de J. "Entre raios de fogo e giros de sol”: videntes de aparições marianas e os escritos de mensagens anticomunistas (Brasil e Portugal). Revista Cultura y Religión, v. 11, n. 2, p. 150-171, 2017.

SILVA, D. R. M. F. "Eu sou a Graça”: as aparições de Nossa Senhora das Graças em Pernambuco. Campinas: Ecclesiae, 2016.

SILVA, S. V. Nossa Senhora das Graças da Vila de Cimbres. In: STEIL, Carlos Alberto; MARIZ, C. L.; REESINK, M. L. (org.). Maria entre os vivos: reflexões teóricas e etnografias sobre aparições marianas no Brasil. Porto Alegre: UFRGS, 2003. p. 69-88.

TEIXEIRA, G. de L. Maria de Araújo: a memória da beata de Juazeiro do Norte na literatura de cordel. 2015. Dissertação (Mestrado em Ciências da Informação) — Universidade Federal de Pernambuco, Recife, 2015.

THOMPSON, E. P. Folclore, antropologia e história social. Aspeculiaridades dos ingleses e outros artigos. Trad. Antônio Luigi Negro; Sérgio Silva. Campinas: UNICAMP, 2007.

RECEBIDO: $15 / 09 / 2019$

APROVADO: 24/10/2019
RECEIVED: 09/15/2019

APPROVED: $10 / 24 / 2019$
RECIBIDO: $15 / 09 / 2019$

APROBADO: 24/10/2019 